\title{
POLÍTICAS PÚBLICAS, PLANEACIÓN Y TERRITORIO. UN “TRINOMIO IMPERFECTO”. Sobre algunos avances investigativos para el análisis de las políticas públicas urbanas a partir de los "Tres M" (Muller, Matus y Monnet).
}

\author{
Jean-François Jolly \\ Profesor titular del Departamento de Arquitectura de la Facultad de Arquitectura y Diseño, Pontificia Universidad \\ Javeriana, Bogotá, Colombia y líder del Grupo de investigación interfacultades (Arquitectura y Ciencias Políticas) \\ "Políticas Urbanas" de dicha universidad \\ jjolly@javeriana.edu.co; fafois.jolly@gmail.com.
}

\section{RESUMEN}

Esta ponencia tiene como propósito presentar algunos avances investigativos que ha tenido el Grupo de investigación PU en cuanto a la misteriosa solución de la relación del "trinomio imperfecto" que conforma el conjunto Políticas públicas, planeación y territorio. Después de presentar los "Tres M"- Muller, Monnet y Matus-, es decir, los tres autores que simbolizan las tres bases conceptuales sobre las cuales descansan las investigaciones, presenta avances y resultados conceptuales e instrumentales de las utilizaciones de esta propuesta realizados por algunos miembros del Grupo. Concluye con los aportes de estos avances investigativos para entender, formular e implementar políticas públicas urbanas como lo propone la recién aprobada "Agenda urbana" adoptada en la Declaración firmada al finalizar la. Tercera Conferencia de Naciones Unidas sobre Hábitat y Desarrollo Sostenible (Hábitat III) tenida en Quito (Ecuador) en octubre de 2016.

Palabras clave: Políticas públicas, Planeación, Territorio, Ciudad.

\begin{abstract}
This paper aims to present some research developments that has had the PU research group in terms of the mysterious solution of the relationship of the "Imperfect Trinomial" that makes up the set public policy, planning and territory. After presenting the "Three M" - Muller, Monnet and Matus-, i.e., the three authors that symbolize the three conceptual bases on which rest the investigations, it presents progress and conceptual and instrumental results of the uses of this proposal made by some members of the Group. It concludes with the contributions of these research advances to understand, develop and implement urban and territorial policies as it proposes the newly approved "Agenda urban" adopted in the Declaration signed to the end of it. Third Conference of UN Habitat and Sustainable Development (Habitat III) held in Quito (Ecuador) in October 2016.
\end{abstract}

Key words: Public policies, Planning, Territory, City. 
Esta ponencia socializa algunos de los avances de investigación, tanto conceptuales como instrumentales, que ha tenido estos últimos seis años el Grupo de investigación Interfacultades (Arquitectura y Ciencias Políticas) "Políticas urbanas" de la Pontificia Universidad Javeriana-Bogotá o "Grupo PU" sobre lo que el autor (Jolly, 2014) llamó "la misteriosa solución" de la relación del "trinomio imperfecto" que conforma el conjunto Políticas públicas, planeación y territorio. Complementan socializaciones anteriores, ya sea de carácter general como la presentada con ocasión del $\mathrm{VI}^{\circ}$ Seminario Internacional de Investigación en Urbanismo [VISIIU] Bogotá-Barcelona en 2014 (Jolly, 2014, 2013a), conocida como "Ponencia de Bogotá", o enfocadas hacia el desarrollo humano (Jolly, 2015b).

Cada una de estas socializaciones constituye un momento en el desarrollo del programa de investigación sobre la cuestión de la territorialización de las políticas públicas en Colombia en una perspectiva mulleriana ${ }^{1}$ iniciado hace casi 15 años por el autor (Jolly, 2008, 2010). Podría decirse que el programa de investigación se ubica en lo que Dormois (2015) llama "el enfoque anglo sajón de las políticas urbanas". Dicho enfoque "consiste a tomar en cuenta las urban policies, [o] las políticas públicas que se implementan en la ciudad, y el urban politics, [0] la actividad política que se desarrolla en una ciudad". Significativamente, en este libro Rémi Dormois, a la vez investigador y académico y funcionario público (policy maker), se interesa sucesivamente por las políticas urbanas de desarrollo económico, sociales, de vivienda, de urbanismo y aménagement (ordenamiento), de movilidad, de medio ambiente, de cultura y a vocación internacional en Francia. En términos de Muller (2010), a nivel urbano, "más pasa el tiempo, más hacer política (politics) es hacer políticas públicas (public policies)".

\section{PEQUEÑA ANTÍFONA A MANERA DE INTRODUCCIÓN EXPLICATIVA...}

La referencia que se hace al álgebra en el título [de esta ponencia] es un recurso metafórico para expresar las intrincadas relaciones que se plantean entre los elementos que componen el trinomio. Por definición, los elementos de un polinomio son irreductibles entre sí y el calificativo de imperfecto se refiere a la dificultad de encontrar la fórmula de dependencia. Como se hace evidente en el desarrollo de la investigación no es la intención sugerir que se encontró una fórmula para resolver la relación óptima del conjunto, por el contrario, como lo explica este séptimo caso, a veces, no hay factorización posible.

Sabina Gómez Puentes, "Un trinomio imperfecto: territorio, planeación e instituciones: Un acercamiento a propósito del manejo territorial en Colombia”, Pontificia Universidad Javeriana, Bogotá, pág. 7.

Entre la casi trentena de investigaciones realizadas estos últimos seis años por el Grupo PU sobre la misteriosa solución de la relación del "trinomio imperfecto" que conforma el conjunto Políticas públicas, planeación y territorio, se ha escogido citar apenas a cinco que fueron ponentes del Foro sobre políticas públicas, planeación y territorio. A propósito de los trabajos de Jérôme Monnet que tuvo lugar el 28 de abril de 2016 en presencia del mismo Jérôme Monnet quien actuó como comentarista.

Si bien la presente ponencia tiene un solo autor, el líder del Grupo PU, cabe indicar que el documento no es un documento del "líder" del grupo sino, más bien, del grupo en voz escrita de su líder... Es pues el resultado de discusiones que se dieron (y siguen dándose...) en el seno del Grupo PU estos últimos 6 años con casi una trentena de estudiantes de la Carrera de Arquitectura y de la Maestría en Planeación Urbana y Regional- MPURde la Facultad de Arquitectura y Diseño, de la Carrera de Ciencia política y de la Maestría en Política Social- MPSde la Facultad de Ciencia Política y Relaciones Internacionales de la Pontificia Universidad Javeriana-Bogotá. Dichos estudiantes, conforme a unos de los "tres principios fundamentales" del Grupo PU, "hacer que los estudiantes de pre y de posgrado sean partícipes de la experiencia investigativa" (Jolly, 2013b), desarrollaron con el autor sus trabajos de grado ${ }^{2}$ en el seno del Grupo siendo participes de su actividad y continuando siéndolo una vez graduados. Siguieron así la lógica de un proceso de construcción de conocimiento "en bucle" que comenzaron hace ya varios años cuatro estudiantes (uno de la, MPUR, dos de la Carrera de Ciencia política y uno de la MPS) cuando de una "discusión dialéctica" con el autor de este documento nacieron las "consideraciones" de la Ponencia de Quito-Cartagena expuestas a continuación.

\footnotetext{
${ }_{1}^{1}$ Para una reciente discusión sobre la "perspectiva mulleriana de territorialización de la acción pública", ver Douillet et al. (2015).

2 En realidad, más allá de "desarrollar" sus trabajos de grado, los estudiantes participes del Grupo PU accedieron seguir al autor de esta ponencia en el sendero, siempre lleno de aventuras y, a veces, de sorpresas, de la "construcción de conocimiento a través de la elaboración de trabajo de pre y de posgrado". Aceptaron como lo escribe una de ellos que este guía transforme "completamente la idea inicial del proyecto para llevarlo hacia campos de mayor fecundidad y profundidad". Aceptaron, también, la posibilidad de enfrentarse el día de la sustentación a la eventual incomprensión de los jurados calificadores pero aprendieron, con creces, a oír y a recibir de los que los precedieron y a dejar el relevo, firme y promisorio, a los que les sucederán...
} 
En otras palabras, se trata entonces de un "documento colectivo" del Grupo PU del cual son, por cierto, coautores Catalina Bejarano Mayorga, Sabina Gómez Puentes, Jorge Enrique Martínez, Nelly Angelica Céspedes y Marlon Arias Sánchez que están citados en él pero, también, los 25 más que no lo son... Es en esta perspectiva que, simbólicamente, el "trinomio imperfecto" que se puso en el título principal retoma la reflexión de una de estos estudiantes sobre la naturaleza misma del ejercicio investigativo, en general, y de éste relativo al conjunto políticas públicas, planeación y territorio, en particular.

Así mismo, no pretende el autor con la ponencia resumir el esfuerzo realizado por los partícipes del Grupo PU o presentar un "balance" o unas "lecciones" que evocan un análisis sistemático, contable y "científico", por cierto necesario, pero demasiado frio, sino sencillamente ayudar a socializarlo. Dicho de manera un poco coloquial quizás, podría decirse que la ponencia aborda la "cocina" de la vida del Grupo PU, es decir, algunos aspectos de su funcionamiento intelectual.

\section{1. “LOS TRES M”: MULLER, MONNET Y MATUS}

Las investigaciones que ha desarrollado desde hace seis años el Grupo PU sobre Políticas públicas, planeación y territorio tienen tres "bases conceptuales", simbolizadas por tres autores cuyo apellido inicia con un M, de ahí la expresión "Tres M" que se utilizará desde ahora en adelante para referirse a ellas... En el orden que indica el título de esta ponencia se trata de:

- Pierre Muller en cuanto al análisis cognitivo de las políticas públicas, en general, el referencial y las lógicas de regulación de las políticas públicas, en particular.

- Carlos Matus en cuanto a la concepción de la planificación y la planeación estratégica situacional.

- Jérôme Monnet en cuanto a la definición del territorio y su doble interdeterminación con territorialidad y territorialización, plasmada en el sistema socio territorial.

En relación con lo anterior, se presentarán a continuación:

- El esquema inicial de Jolly sobre el análisis de las políticas públicas en el territorio, que se basa en Muller y en Le Galès.

- La Ponencia-propuesta de Quito-Cartagena que aproximaba dicho esquema con las reflexiones de Monnet.

- Unas consideraciones sobre los instrumentos de planificación y la planeación "à la Matus."

\subsection{El esquema inicial "para el análisis de las políticas públicas en el territorio" de Jolly (2004, 2008, 2010)}

El esquema inicial que desarrolló Jolly $(2004,2008,2010)$ "para el análisis de las políticas públicas en el territorio" descansa sobre tres pilares conceptuales:

1. El referencial como parte del enfoque cognitivo del análisis de las políticas públicas. Según Muller (2010) "el análisis cognitivo de las políticas públicas [está] fundamentada en el estudio de la acción pública como un proceso de marcos de interpretación del mundo a partir de los cuales, tanto los actores públicos (gobierno, administraciones...) como los actores privados (grupos de intereses...), van a desarrollar sus estrategias para definir el contenido de las políticas públicas" (cursivas agregadas). El análisis de los referenciales es uno de los puntos claves del análisis cognitivo de una política pública.

2. Las lógicas de regulación de las políticas públicas- PP- (Muller, 1997 y 2010).

3. Los modos de gobierno de las ciudades (Le Galès, 1995).

- Para Muller (2010), el referencial de una política pública o "la manera cómo los actores perciben los problemas, discuten de las soluciones y lo que orienta sus acciones", se divide en tres: Referencial global (RG), Referencial sectorial (RS) y unos operadores de transacción que articulan RT y RG.

- El mismo Muller $(1997,2010)$ distingue dos tipos de lógica de regulación de las PP: la lógica sectorial o sectorialidad, "que se organiza alrededor de un sector", vertical, y la lógica territorial o territorialidad, centrada sobre un territorio, horizontal (relación centro-periferia). 
- Le Galès (1995) opone dos modos de gobierno de las ciudades: el gobierno de la ciudad, como primacía del Estado soberano, top-down, uniactor (público del nivel central) y unisectorial y la gobernancia (za) de las ciudades, multiactor de diferentes tipos y multisectorial.

A partir de estos tres pilares conceptuales, Jolly hace las cuatro propuestas siguientes:

1. Extrapolar ciudad a territorio, lo que permite oponer el gobierno del territorio y la gobernancia (za) de los territorios. Según Jolly (2010)

..."el gobierno del territorio" no hace objeto de una definición directa. Sin embargo, por contraste, se puede hablar del gobierno del
territorio como de una manera de gobernar un territorio a la cual, según Stren, se le asocia "una descripción formal de los poderes y
responsabilidades de las autoridades" y, según Le Galès, las ideas de "uniformización, racionalidad y estandarización, [...] conducta,
pilotaje, dirección con la primacía acordada al Estado soberano", de verticalidad para decirlo así. De su lado, Muller y Surel citados por
Jolly (2010), anotan que sí se trata de "un modo de gobierno en el cual la puesta en coherencia de la acción pública [...] pasa por la
acción de una élite político-administrativa relativamente homogénea y centralizada". Finalmente, Le Galès (1995) anota que la gobernancia del territorio se traduce por una "pluralidad de actores, organizaciones [lo que] revela que la política local (con el triple sentido de polity, policies y politics) depende cada vez más de actores no gubernamentales" (énfasis agregado)"

2. Relacionar sectorialidad con gobierno del territorio y territorialidad con gobernanza de los territorios. En otros términos, a la lógica sectorial le corresponde el modo de gobierno del gobierno del territorio y a la lógica territorial el modo de la gobernanza de los territorios.

3. Introducir el concepto de hibridad de las lógicas y de los modos de gobierno ("Secterritorialidad" y "gobiernancia (za)") como combinación respectivamente de las lógicas sectorial y territorial y de la gobernancia (za) de los territorios.

4. Proponer analizar las PP territoriales o el despliegue territorial de las PP nacionales según su grado de sectorialidad/territorialidad y su grado de gobierno/gobernancia (za).

\subsection{La Ponencia-propuesta de Quito-Cartagena: diez "consideraciones" o ideas fundamentales}

En su Ponencia-propuesta de Quito-Cartagena, Jolly (2012, 2015a) propone aproximar al esquema de análisis anterior el "sistema socio territorial" o "circuito de interdeterminación entre territorio, territorialidad y territorialización” del geógrafo francés Jérôme Monnet (2010) (“Trípode de Monnet”), en el cual se definen:

- El territorio como "el espacio material donde se realiza una acción humana repetitiva".

- La territorialidad como "los valores atribuidos a un territorio".

- La territorialización como las "acciones que se hacen sobre el espacio material fundamentadas en una territorialidad".

Entre estos tres elementos existe una doble interdeterminación (Ver Gráfico 1) que constituyen así lo que el Grupo PU llama el "Trípode de Monnet".

Monnet considera que

.... a una perspectiva centrada sobre el espacio (el territorio considerado como 'espacio') se agrega una perspectiva socio centrada (el sistema de producción de los territorios por los seres humanos) que incita a renovar las nociones y a preguntarse sobre el papel de las redes, de la movilidad y de los intercambios.

De las reflexiones de Monnet sobre el sistema socio territorial y la interdeterminación entre territorio, territorialidad y territorialización y del esquema para el análisis de las políticas públicas en el territorio y de la territorialización de la acción pública elaborado anteriormente (Jolly, 2010), se sacaron las diez "consideraciones" o ideas fundamentales que, "unidas, constituyen el esbozo de una nueva propuesta" (Jolly, 2012):

1. "Como consecuencia de la primera bucle (ver las flechas al contrario del sentido de las manillas de un reloj en el gráfico 1) las políticas públicas territoriales pueden ser entendidas como una territorialización, es decir, como el conjunto de acciones que se ejercen sobre un espacio material (territorio) y actualizan el sistema de valores que las fundamentan (territorialidad), sistema que, a su vez, estructura las representaciones y 
significados de este territorio, el cual, in fine, condiciona materialmente las acciones que se pueden ejercer sobre él, es decir, la territorialización.

2. Como consecuencia de la segunda bucle (ver las flechas en el sentido de las manillas de un reloj en el Gráfico 1), las políticas públicas territoriales 'producen y definen' el territorio, el cual, a su vez, materializa los valores (capital territorial) base de la territorialidad que van a condicionar socialmente las acciones que se puede ejercer sobre éste.

3. En términos dinámicos, es decir, considerando diferentes periodos sucesivos de tempo, es posible entonces examinar cómo las políticas públicas territoriales han sucesivamente producido y definido el territorio y reconstruir estos sucesivos procesos de producción y de definición del territorio. Así mismo, es posible reconstruir los condicionamientos que un territorio dado ha fijado para la formulación y la implementación de públicas territoriales o para la territorialización de políticas públicas nacionales.

4. De lo anterior se deduce la posibilidad de analizar rupturas, desfases, conflictos entre los dos tipos de bucle, de un lado, y entre los diferentes periodos en cada bucle o, inclusive, entre periodo de un bucle y otro periodo de otro bucle.

5. La territorialidad entendida como 'un sistema de valores que unos actores sociales le asignan a un territorio determinado' y que según Monnet condiciona socialmente las acciones que dichos actores pueden ejercer sobre este territorio, es decir, la territorialización, puede considerarse como un 'referencial territorial' 'à la Muller', es decir, como "una imagen de la realidad sobre la cual se quiere intervenir. Es en referencia a esta imagen cognitiva que los actores van a organizar su percepción del problema, confrontar sus soluciones y definir sus propuestas de acción: este conjunto de imágenes es "el referencial de la política pública" (cursivas originales (Muller, 2010).

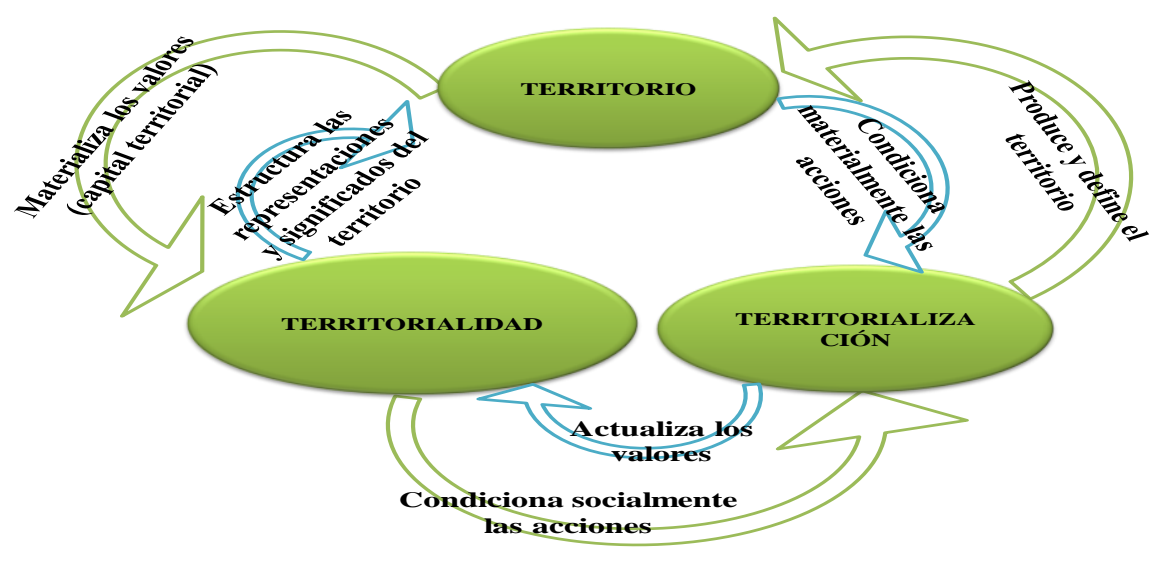

Gráfico 1: La interdeterminación entre territorio, territorialidad y territorialización según Monnet Roa (2011b: 2).

6. Así podrá decirse en la perspectiva mulleriana que el referencial territorial que sostiene la territorialización "puede descomponerse en tres elementos: el referencial global [territorial], el referencial sectorial [territorial] y unos operadores de transacción que definen lo que llamaremos la Relación global-sectorial [territorial] (RGS [T]" (Muller, 2010).

7. Si según Muller (2010) puede hablarse de lógica territorial o territorialidad cuando "la intervención pública se organiza alrededor de un lógica especifica de regulación [...], la lógica territorial u horizontal”, entonces es posible plantear que la territorialización "à la Monnet" supone que los actores que la ejercen actúen según una lógica territorial.

8. Según el esquema de análisis de las políticas públicas en el territorio elaborado por Jolly (2010) y resumido en [la] subsección anterior, el modo de gobierno que corresponde entonces a una territorialización 'à la Monnet' es la gobernancia de los territorios.

9. Tomando en cuenta que, según el mismo esquema, de una parte la territorialización de la acción pública supone tanto la formulación y la implementación de políticas públicas 'definidas en el mismo territorio' como 
la territorialización de políticas públicas definidas 'desde arriba', es decir, lo que Pedro Medellín citado por Jolly (2010) llama el 'despliegue territorial', y, de otra, que las políticas públicas son hibridas en cuanto tanto a su lógica de regulación como a su modo de gobierno, es posible evidenciar los conflictos que van a nacer entre las diferentes lógicas de regulación y, por ende, los diferentes modos de gobierno según los cuales actuarán los actores involucrados en procesos de territorialización.

10. Así mismo, será posible evidenciar los conflictos que nacen entre lo que podría llamarse siguiendo a Muller el 'referencial territorial sectorial' o siguiendo a Monnet la "territorialidad sectorial", que proviene de los actores que actúan según una lógica territorial pero en cuanto a un sector específico, y el 'referencial sectorial territorial', o la 'sectorialidad territorial', que es el hecho de actores que actúan según una lógica sectorial pero que deben 'territorializar' su acción".

\subsection{Consideraciones sobre los instrumentos de planificación y la planeación "à la Matus"}

Como bien lo indica el título del libro faro de Carlos Matus, Política, planificación y gobierno, podría decirse que la planificación es la bisagra entre un proyecto político y el acto de gobernar. En términos del mismo Matus (1992), "la planeación es el proceso que permite mediar entre la Política - o los ideales definidos-, y el gobierno o las acciones emprendidas para alcanzarlos" (cursivas añadidas), de tal manera que la planificación es "un cálculo que precede y preside la acción". "Él que planifica gobierna y él que gobierna planifica" es, quizás, la frase que mejor resume la tesis de Carlos Matus.

Su propuesta de "planificación estratégica situacional" parte de hacer evidentes las limitaciones de lo que él ha llamado la "planeación normativa". En efecto, su revisión de la planeación en América Latina lo lleva a identificar que esta ha estado basada en la norma, en un deber ser, que poco se basa en la realidad social del continente y anota "los magros resultados de la planeación en América Latina deben buscarse en el mencionado supuesto de base de la planeación normativa que por un lado conduce a un concepto restringido de planificación $\boldsymbol{y}$ planificador, y por el otro, conduce a una planeación tecnocrática que se aísla de la planeación política y del proceso de gobierno" (Matus, 1987. Negrillas cursivas originales, cursivas añadidas).

No aislar la planeación política del proceso de gobierno es entonces según Carlos Matus la clave para poder planificar. Lo anterior se explica si se recuerda que Matus, ingeniero comercial chileno, fue ministro de economía de Allende, pasó dos años en la cárcel donde como lo indica en la Introducción escribió los primeros apuntes de su libro para reflexionar sobre el porqué del fracaso del Gobierno de Allende... Las principales diferencias entre la planeación normativa y la planeación situacional están resumidas en la Tabla 1 elaborada por Sabina Gómez (2012) quien resume así el pensamiento de Carlos Matus:

Como el objeto de la planeación es la acción y no un objeto fijo, esta tendrá como referente la acción, intencional y reflexiva de otros agentes. Es decir, el ser es un conjunto de actores, no se refiere a objetos o estructuras fijas, sino a una situación, un momento enmarcado en el tiempo, en un contexto constituido por la capacidad de acción de otros. La planeación como acción dirigida tendrá que medir o por lo menos contemplar la capacidad de quienes hacen parte de la situación.

\begin{tabular}{|ll|}
\hline \multicolumn{1}{|c|}{ Planificación normativa } & \multicolumn{1}{c|}{ Planificación situacional } \\
\hline El sujeto es diferente del objeto & El sujeto hace parte del objeto \\
\hline Verdad objetiva, un diagnóstico verdadero & Diferentes verdades y explicaciones \\
\hline Etapas & Situaciones \\
\hline El objeto urbano sigue leyes & Los actores crean posibilidades \\
\hline $\begin{array}{l}\text { Cálculo normativo de un deber ser diferente a } \\
\text { lo que tiende a ser la realidad }\end{array}$ & $\begin{array}{l}\text { Diseño indicativo del deber ser, del puede ser } \\
\text { y la voluntad de hacer }\end{array}$ \\
\hline Predominio del sector y/o territorio & Integrada y coordinada \\
\hline Sujeción a los límites normativos & Superación de los límites administrativos \\
\hline
\end{tabular}

Tabla 1: Diferencias entre la planeación normativa y la planeación situacional Bejarano (2012: 156) a partir de Matus $(1987,1992)$.

En efecto, como son varios los actores que coexisten en la realidad con capacidades de planificación diferenciadas habrá varias explicaciones de la realidad y todas estarán condicionadas por la inserción particular de cada actor en dicha realidad, es decir, por su situación. En consecuencia ya no es posible el diagnóstico único ni la verdad objetiva. Solo es posible una explicación situacional.

'La técnica de la planificación como se ha dicho tiene una parte vinculada a lo normativo, (el deber ser) que se refiere en consecuencia a una "norma" que debe ser cumplida y que ha sido fijada por diferenciación entre lo necesario y la realidad. Pero en sus pretensiones también está 
relacionada y dirigida a transformar la realidad. La planeación se ubica en lo razonablemente posible, el campo entre el elemento formal de la norma y el ser que no puede conocer objetivamente"'. (Matus, 1987. Cursivas dentro del texto).

En consecuencia la planeación 'trata de la acción intencional y reflexiva, mediante la cual el productor espera lograr determinados resultados en una situación de cooperación o conflicto con otros. La acción es una categoría situacional. (Matus, 1987. Énfasis fuera de texto)

En el ámbito público la acción escapa del control exclusivo de un solo agente, razón por la cual cambia la función de los gobiernos: su labor consiste en regular, promover, vincular o reducir la acción de otros para lograr así la consecución de los propósitos del gobierno. Y no lo hacen directamente, sino incidiendo sobre las situaciones. La planificación es entonces un hecho político que tendrá que involucrar actores, valores normativos, esquemas para la cooperación y resolución de conflictos para que pueda en realidad, materializar un plan y gobernar.

Los principios del cálculo situacional y de lo razonablemente posible son los fundamentos de la propuesta de Matus, a saber, la planificación situacional.

\section{ALGUNOS AVANCES Y RESULTADOS DE CARÁCTER CONCEPTUAL}

De las varias investigaciones adelantadas por el Grupo PU que constituyen avances y resultados más bien de carácter conceptual se citarán aquí las de Bejarano $(2016,2013,2012)$, de Gómez $(2016,2013,2012)$ y de Martínez $(2016,2013,2012)$, haciendo énfasis en los aportes específicos que cada una ha ofrecido.

\subsection{Catalina Bejarano, su esquema de análisis del referencial de las políticas públicas urbanas desde la perspectiva de los instrumentos de planificación y de gobierno como instrumentos de acción pública y el análisis de las trayectorias del referencial de los instrumentos de acción pública}

La investigación desarrollada por Catalina Bejarano (2012, 2013, 2016), antropóloga y especialista en Desarrollo regional, marca, sin duda alguna, un hito fundamental para avanzar en la solución de la relación del "trinomio imperfecto" que conforma el conjunto políticas públicas, planeación y territorio. Los avances conceptuales de Catalina Bejarano son de dos tipos:

1. Proponer un esquema de análisis del referencial de las políticas públicas urbanas desde la perspectiva de los instrumentos de planificación y de gobierno como instrumentos de acción pública que se apoya en "los Tres M" evocados anteriormente.

2. A partir de lo que puede calificarse como un "esquema general", desarrollar uno de los elementos, el temporal, y así conceptualizar el análisis de las trayectorias del referencial de los instrumentos de acción pública.

- En cuanto al esquema general (ver Figura 1), cabe por cierto citar a la autora (Bejarano, 2012) que, a la hora de elaborar un "resumen de los principales elementos del esquema de análisis", indica lo siguiente:

...por un lado, se establece la centralidad de los instrumentos de acción pública como unidad de análisis de las políticas públicas de la ciudad. Por otro lado, se ilustran las cuatro dimensiones de análisis relacionadas con los instrumentos de acción pública, que permitirán construir reflexiones y conclusiones en torno a las políticas públicas sobre alguno de los atributos o sectores de la ciudad. Así, la dimensión cognitiva permite construir el referencial de cada instrumento de acción pública, la dimensión temporal permite elaborar las trayectorias del referencial, la dimensión espacial permite espacializar el referencial en un territorio y la dimensión política permite el acercamiento a los actores y a los mediadores que inciden en la construcción del referencial.

El esquema de análisis como herramienta permitirá al investigador presentar una aproximación cognitiva de las formas de territorialización y de acción pública en el territorio en relación con el desarrollo de un sector de la ciudad de Bogotá entre 1995 y 2012.

- En cuanto al análisis de las trayectorias del referencial de los instrumentos de acción pública, como bien lo indica la autora:

... la propuesta de un esquema de análisis de las trayectorias del referencial de los instrumentos de acción pública facilita la identificación de los desfases, continuidades y rupturas en la construcción del referencial de las políticas públicas urbanas. Es una metodología para observar y explicar de forma detallada los procesos (sucesivos y secuenciales) de la acción pública, desde la perspectiva de los instrumentos de planificación y de gobierno. En ese sentido, el esquema es una propuesta para reflexionar sobre la territorialización de las ideas y sobre el origen, el contenido y los valores que sustentan las políticas públicas de la ciudad (cursivas añadidas) (Bejarano, 2013).

En otros términos,

...habiendo definido la territorialización como el engranaje de 3 piñones (las políticas públicas, la planificación y el gobierno), es decir como un mecanismo articulado y dinámico, fue posible identificar la necesidad de abordar las relaciones entre los instrumentos de acción pública desde una perspectiva de coordinación temporal (cursivas y negrillas originales. Bejarano, 2012). 


\section{El propósito de Bejarano (2013) era en efecto}

...proponer un esquema de análisis de las trayectorias de las políticas públicas en el territorio (...) que permita reconstruir y examinar las trayectorias de las políticas públicas en la ciudad desde la perspectiva de los instrumentos de planificación y de gobierno (ídem).

\section{Para la autora,}

...las trayectorias se entienden como el curso o el recorrido que, a lo largo del tiempo, han seguido el conjunto de decisiones y acciones tomadas sobre un atributo o dimensión particular en la ciudad. Desde un enfoque cognitivo, el esquema busca proporcionar los elementos para reconstruir el referencial de las políticas públicas en el sentido de Muller, es decir, la manera cómo se han formulado los problemas, cómo se han orientado las soluciones, cómo se han planteado los procedimientos y los principios centrales que han sido utilizados para concebir las decisiones y las acciones en la ciudad. Así mismo, se hace el planteamiento de relaciones de sincronía y de diacronía para el análisis temporal de los instrumentos de acción pública y la construcción de las trayectorias del referencial de las políticas públicas urbanas- PPU (ídem. Cursivas originales).

\section{El Análisis Cognitivo de las Políticas Públicas Urbanas}

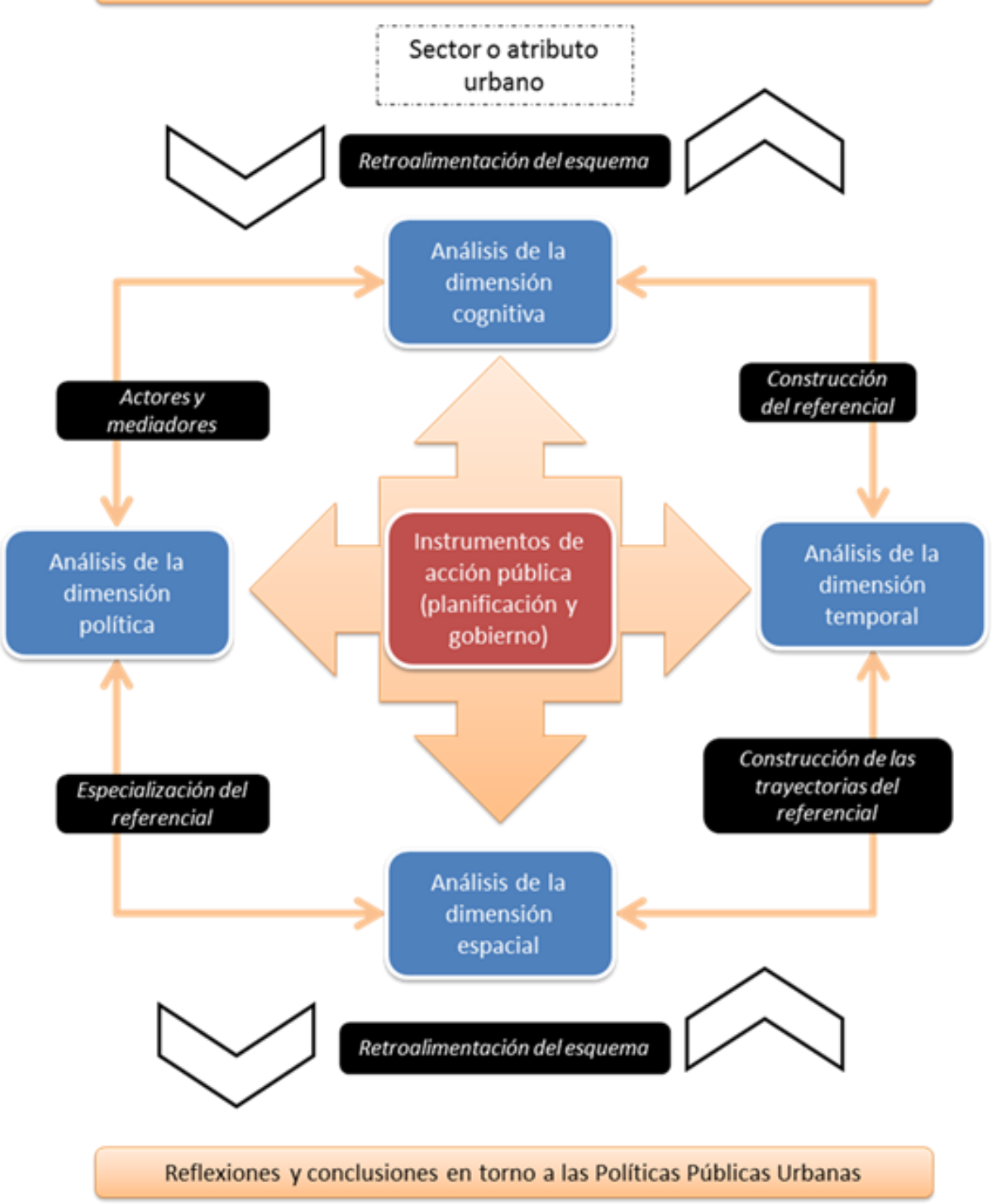


Figura 1: Resumen del esquema de análisis de la construcción del referencial de las políticas públicas urbanas desde la perspectiva de los instrumentos de planificación y de gobierno como instrumentos de acción pública Bejarano (2012: 105)

Catalina Bejarano $(2013,2016)$ ha seguido desarrollando reflexiones sobre este esquema de análisis de las trayectorias de las políticas públicas en el territorio. Su propuesta analítica ha servido de base a varias de las investigaciones realizadas en el marco del Grupo PU.

Como conclusión, es posible decir que la investigación de Catalina Bejarano, enmarcada totalmente en los principios de Matus, se apoya principalmente sobre la consideración 4, esta es "la posibilidad de analizar rupturas, desfases, conflictos entre los dos tipos de bucle" y, segundariamente, sobre las consideraciones 6 y 7.

\subsection{Sabina Gómez y el "trinomio imperfecto" territorio, planeación e instituciones}

A diferencia de Catalina Bejarano que buscaba construir un esquema general de análisis del referencial de las políticas públicas urbanas desde la perspectiva de los instrumentos de planificación y de gobierno como instrumentos de acción pública, Sabina Gómez $(2012,2013,2016)$ no utiliza el análisis cognitiva des políticas públicas para conducir su reflexión porque, como bien lo indica,

...la inquietud inicial de la investigación tiene que ver con la planeación del territorio y las políticas públicas y, más concretamente, con la relación que existe entre el territorio, la planeación territorial y la territorialización de estas últimas (Gómez, 2013.Cursivas añadidas).

La conclusión de su reflexión, "de corte teórica" y que se refleja en el título de su investigación, es que territorio, planeación e instituciones conforman un "trinomio imperfecto", siendo según la autora en una suerte de prologo (Gómez, 2012) aquella referencia al algebra un

....recurso metafórico para expresar las intrincadas relaciones que se plantean entre los elementos que componen el trinomio. Por definición, los elementos de un polinomio son irreductibles entre sí, y el calificativo de imperfecto se refiere a la dificultad de encontrar la fórmula de dependencia. Como se hace evidente en el desarrollo del trabajo, no es la intención sugerir que se encontró una fórmula para resolver la relación óptima del conjunto, por el contrario, como lo explica este séptimo caso, a veces no hay factorización posible.

\section{El propósito de su investigación es entonces}

...ofrecer elementos para entender la territorialización de la acción pública desde el enfoque institucionalista de las políticas públicas porque entender cómo se lleva la acción pública al territorio no es un asunto de poca relevancia, más aún si, como le explica el sistema socio territorial de Monnet, este es, a la vez, resultado y condicionante de la acción (negrillas añadidas y cursivas originales. Gómez, 2013).

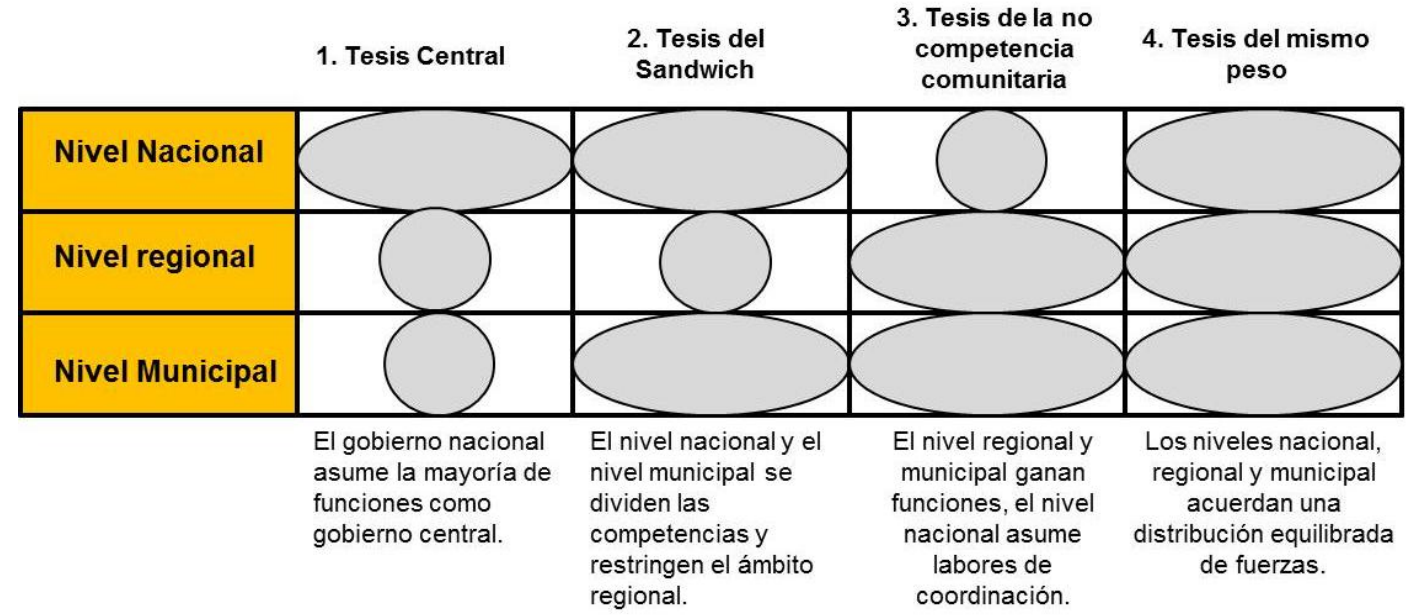

Esquema 1. Síntesis de posibles distribuciones de competencias en el ámbito gubernamental Gómez (2012: 69).

Para lograr este propósito, la autora va apoyarse en otro enfoque del análisis de las políticas públicas, el análisis institucionalista de Elinor Ostrom. Después de una revisión a partir de Monnet de dos momentos de la planeación territorial en Colombia, la Ley 388 de 1997 y la Ley Orgánica de Ordenamiento Territorial de 2011, hace una 
presentación general del enfoque institucionalista llevado a las políticas públicas del territorio a partir de Subirtas y de Ostrom, para, finalmente, ofrecer unas conclusiones respecto a la territorialización de la acción pública desde el enfoque institucionalista, teniendo como eje de reflexión la posible consolidación de un área metropolitana o ciudad-región para Bogotá.

El Esquema 1 y la Tabla 2 ilustran las reflexiones de Sabina Gómez sobre este tema respectivamente en cuanto a "posibles distribuciones de competencias en el ámbito gubernamental" y a "formas de territorialización de los atributos urbanos".

Siguiendo los pasos esbozados en su investigación de 2012 y combinándolos, los más recientes desarrollos investigativos de Sabina Gómez (2016) tienen que ver con las implicaciones de la distinción entre territorio areolar y territorio reticular en la planeación territorial de los procesos de metropolización.

\begin{tabular}{ccc}
\hline Atributos urbanos & Territorialización & \\
\hline Suelo urbano & Usos del suelo, densificación & Aerolear \\
Vivienda y hábitat & Desconcentración urbana & Reticular \\
Renovación urbana & Aerolear \\
Movilidad & Provisión de suelo & Reticular \\
& Provisión y distribución de equipamientos & Aerolear \\
Medio ambiente & Retemas multimodales de integración regional & Reticular \\
& Zuncionamiento ecosistemas & Aerolear \\
Espacio público & Provisión de espacios públicos & Rerolear
\end{tabular}

Tabla 2: Formas de territorialización de los atributos urbanos Gómez (2012: 75).

\subsection{Jorge Martínez y la formulación de la política social de salud pública desde un enfoque socio- territorial temporal a partir de los instrumentos de planificación}

Jorge Martínez, economista quien, a diferencia de sus dos compañeras anteriores, realizó su investigación en el marco de la Maestría en Política Social, si bien toma como categoría de análisis los instrumentos de planificación, no se apoya en los principios planteados por Carlos Matus. En efecto, el objetivo de su investigación era

....proponer un esquema de análisis en salud pública desde un enfoque socio-territorial temporal, el cual se aborda desde los instrumentos de planificación sectorial y territorial, identificando las concordancias, desfases, continuidad y rupturas entre estos, basándose en los determinantes en salud de la Organización Mundial de la Salud (OMS) (Martínez, 2013a. Cursivas añadidas).

Según el autor,

... el esquema de análisis [toma] los instrumentos de planificación como objeto de análisis, siendo éstos los que orientan las acciones tanto territoriales como sectoriales y que definen alcances y propósitos en un marco temporal. De igual manera, la lectura de los instrumentos desde un análisis cognitivo de políticas públicas permite identificar diferentes tipos de referenciales: global, sectorial, territorial global y secterritorial. Abordar la salud desde esta óptica constituye un avance en el entendimiento de las relaciones y de los procesos propios de un sector y de un territorio, en cuanto a la mirada de la política social de salud pública Martínez (2012. Cursivas añadidas).

Los principales aportes conceptuales de la investigación residen en la construcción de un "esquema general" (ver Gráfica 2) que descansa sobre "dos elementos", el primero siendo

...el análisis cognitivo de las políticas públicas a través de instrumentos de planificación, donde este permite realizar la identificación de referenciales en cada nivel de planeación y decisión, los cuales se interpretan por medio de los niveles de percepción, valores, normas, imágenes y algoritmos [mientras el] segundo son las categorías de los determinantes intermedios en salud.

El análisis tiene tres partes. Si bien

...la primera parte del análisis se enfoca en la coordinación sincrónica en un momento del tiempo, para lo cual se identificarán valores, normas, algoritmos e imágenes en los referenciales en relación a las categorías definidas en los determinantes en salud, esto permite identificar las concordancias y desfases entre los instrumentos de planificación en diferentes niveles de decisión y bajo dos lógicas disimiles, una orientada 
desde la especialidad (RS) y la otra desde el territorio (RGT). El principal resultado de este proceso es identificar el grado de articulación y el desfase que se encuentra entre los referenciales y los niveles de percepción en la política social de salud pública.

[Así mismo], la tercera parte del análisis utiliza la coordinación diacrónica para definir los cambios en el referencial global territorial (RGT), RST y RTS, los cuales solo se perciben y se pueden identificar al transcurrir las acciones y el tiempo. En este caso se identificará la continuidad o rupturas en los niveles de percepción, identificando los cambios marginales y paulatinos que pueden llegar a ser imperceptibles, pero determinantes para la transformación social y la ampliación de las garantías al derecho a la salud (ídem. Cursivas mías).

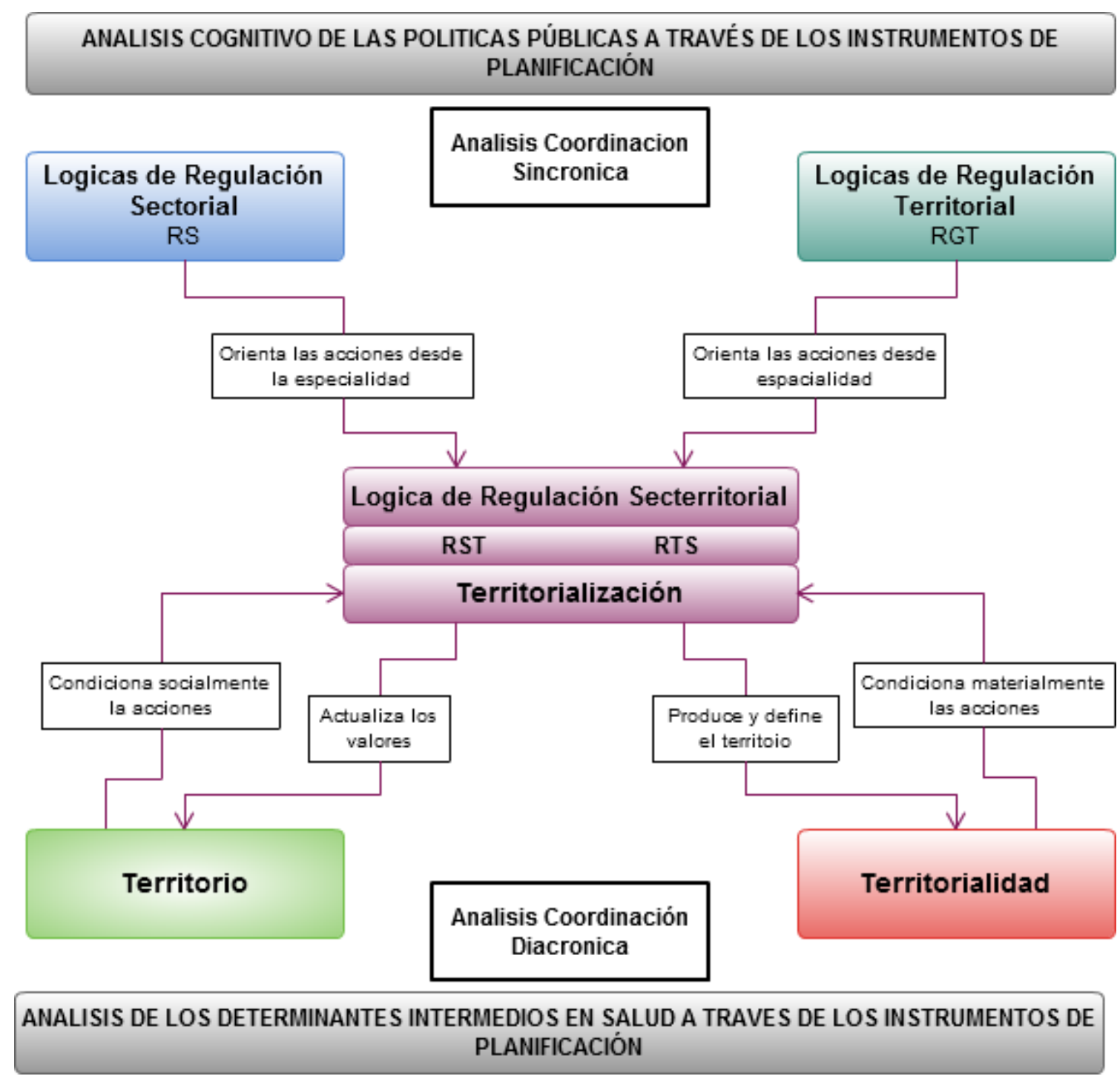

Gráfica 2 Esquema general de análisis en salud pública desde un enfoque socio-territorial temporal Martínez $(2012,63)$.

Lo anterior significa concretamente apoyarse sobre el análisis sincrónico y diacrónico de las trayectorias del referencial de los instrumentos de acción pública de Bejarano, por el contrario, la segunda parte del análisis al centrarse

...en las relaciones entre las dos lógicas y las acciones sobre el territorio y la territorialidad [y al partir] de la secterritorialidad representada por el Referente Sectorial Territorial (RST) y el Referente Territorial Sectorial (RTS), en los cuales se puede determinar según Jolly el grado de sectorialidad o de territorialidad que este contenido en los instrumentos de planificación descritos. Esto constituye el elemento central y el articulador entre las lógicas de regulación y la interdeterminación en el territorio propuesta por Monnet (ídem),

...desarrolla aspectos conceptuales nuevos que Catalina Bejarano no había abordado y toma como base y desarrolla las consideraciones $1,5,7,9$ y 10 . 
Siguiendo los pasos esbozados en su investigación de 2012 y 2013, los más recientes desarrollos investigativos de Jorge Enrique Martínez (2016) se interesan por la articulación de la política de salud pública desde un enfoque socio-territorial temporal en las ciudades de Medellín y de Bogotá para el período 2004-2016.

\section{AVANCES Y RESULTADOS DE CARÁCTER MÁS BIEN INSTRUMENTAL}

De las varias investigaciones adelantadas por el Grupo PU que constituyen avances y resultados de carácter más bien instrumental se citarán aquí las de Céspedes $(2016,2015)$ y Arias $(2016 a, 2016 b)$, haciendo énfasis en los aportes específicos que cada una ha ofrecido.

\subsection{Nelly Angelica Céspedes o cómo reordenar un territorio de ladera urbana en riesgo en Colombia}

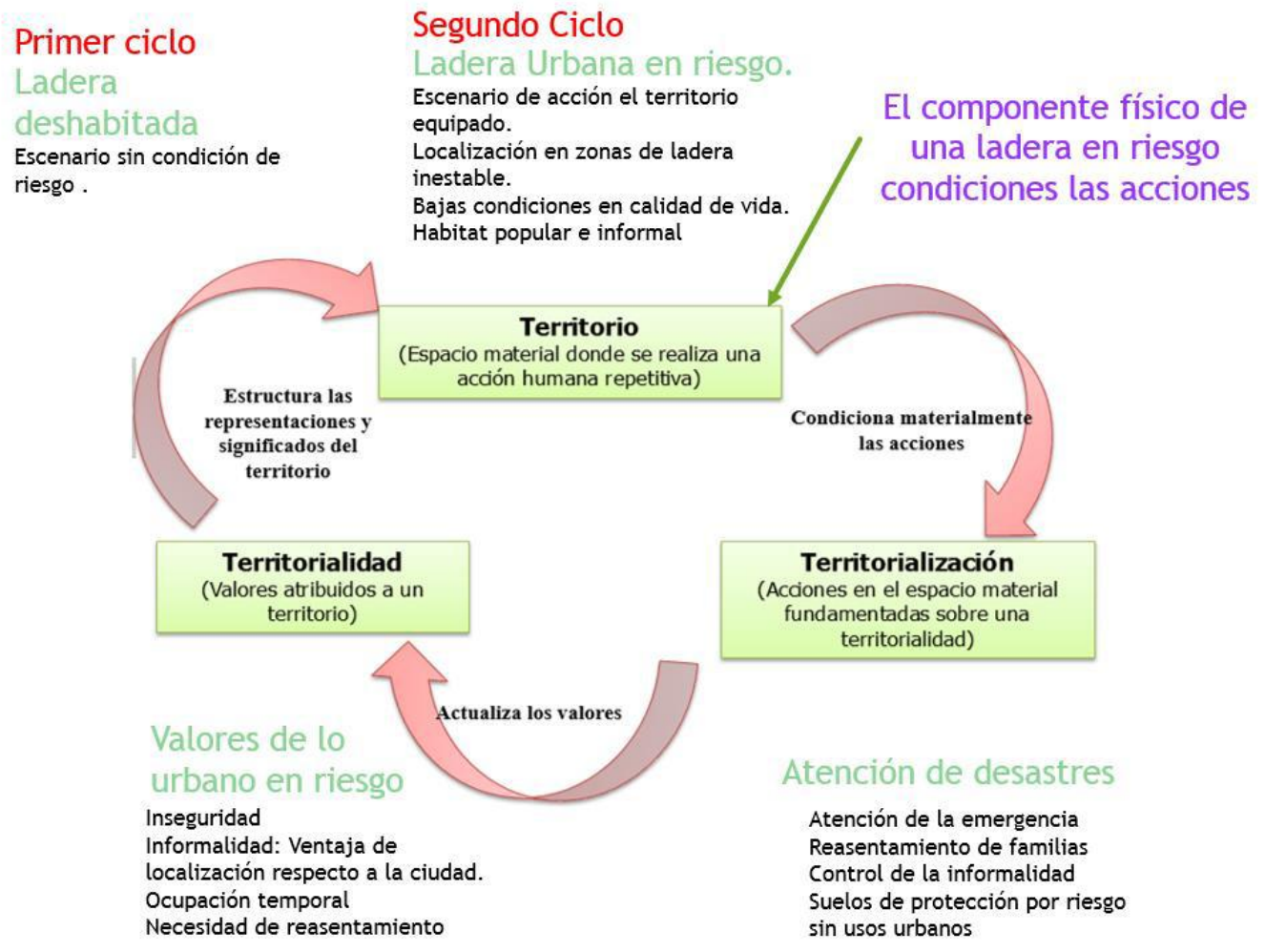

Figura 3: Análisis del ciclo de interdeterminación en la construcción de territorios en riesgo Fuente: Céspedes (2015:40).

La intención de la investigación de Nelly Angelica Céspedes, ingeniera civil y especialista en geotecnia vial y pavimentos, está bien resumida en esta citación de la Introducción (Céspedes, 2015):

...proponer un esquema de análisis de las condiciones que permitan considerar la planeación urbana como una medida de reducción del riesgo de desastres en Colombia y que posibilita desde acciones de reordenamiento de laderas urbanas la construcción de territorios más seguros.

Mientras tanto, el párrafo siguiente de la misma Introducción explica "el meollo central" de la investigación:

Lo anterior abordado desde el marco de análisis de la territorialización de la política pública de gestión del riesgo de desastres mediante el sistema socio territorial de Jérôme Monnet (2010), el cual permite reflexionar en torno a los conceptos de territorio, territorialidad y territorialización 
La Figura 3 muestra el "Análisis del ciclo de interdeterminación [de Monnet] en la construcción de territorios en riesgo" que hace Céspedes, es decir, su interpretación del Trípode de Monnet al caso que trabaja, el de una ladera urbana en riesgo geotécnico que se quiere intervenir.

Las Figuras 4 y 5 muestran, respectivamente, el "Análisis del ciclo clásico de interdeterminación en la intervención de un territorio mediante reducción del riesgo en 2D" o "Ciclo de riesgo" que se opone al "Análisis del ciclo alternativo de interdeterminación en la intervención de la planeación mediante reordenamiento de la intervención en 2D" o "Ciclo de Planeación urbana en 2 D". Ambos análisis consideran el Territorio "à la Monnet" (espacio para la acción) como la "Dimensión física", mientras la Territorialización (acciones) se ve como la "Dimensión de planeación" y la Territorialidad (valores) como la "Dimensión social".

Lo que distingue los dos ciclos son:

1. El nombre mismo del ciclo: de "De reducción sin componente temporal" a "De reordenamiento en 2D".

2. El Territorio: de "Ladera urbana más segura" a "Ladera urbana en condiciones cambiantes de riesgo".

3. El tipo de Territorialización: de "Conocer la zonificación de riesgo y condicionamiento al uso de mejoramiento integral" a "Reordenamiento de las intervenciones sobre el territorio a partir de condiciones físicas de la ladera urbana".

He aquí el primer aporte de Céspedes: invertir la "tradicional" o "clásica" visión de "introducir en los instrumentos de planificación la reducción de riesgo" por otra, "alternativa": "la planeación urbana como una medida de reducción del riesgo de desastres y de reordenamiento de un territorio de ladera urbana en riesgo".

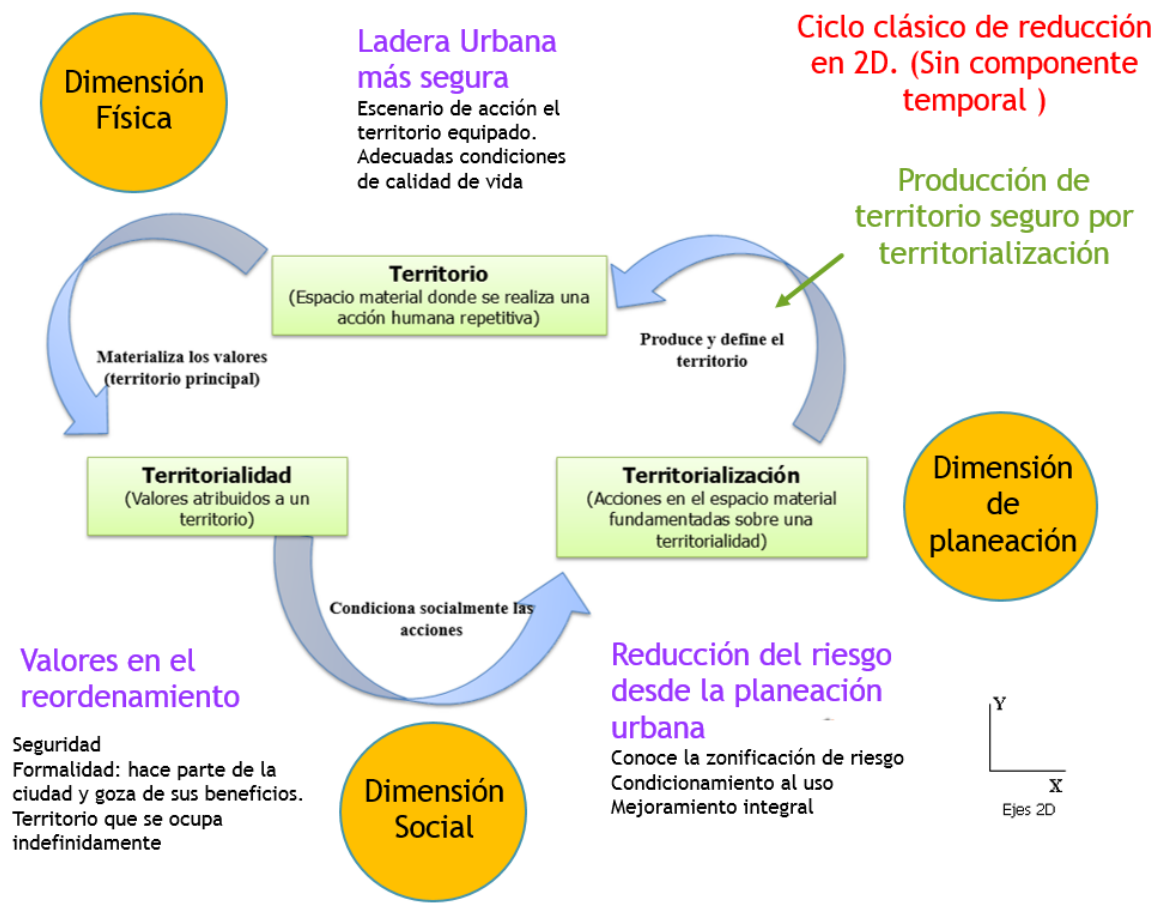

Figura 4: Análisis del ciclo clásico de interdeterminación en la intervención de un territorio mediante reducción del riesgo en 2D. Céspedes (2015: 41). 


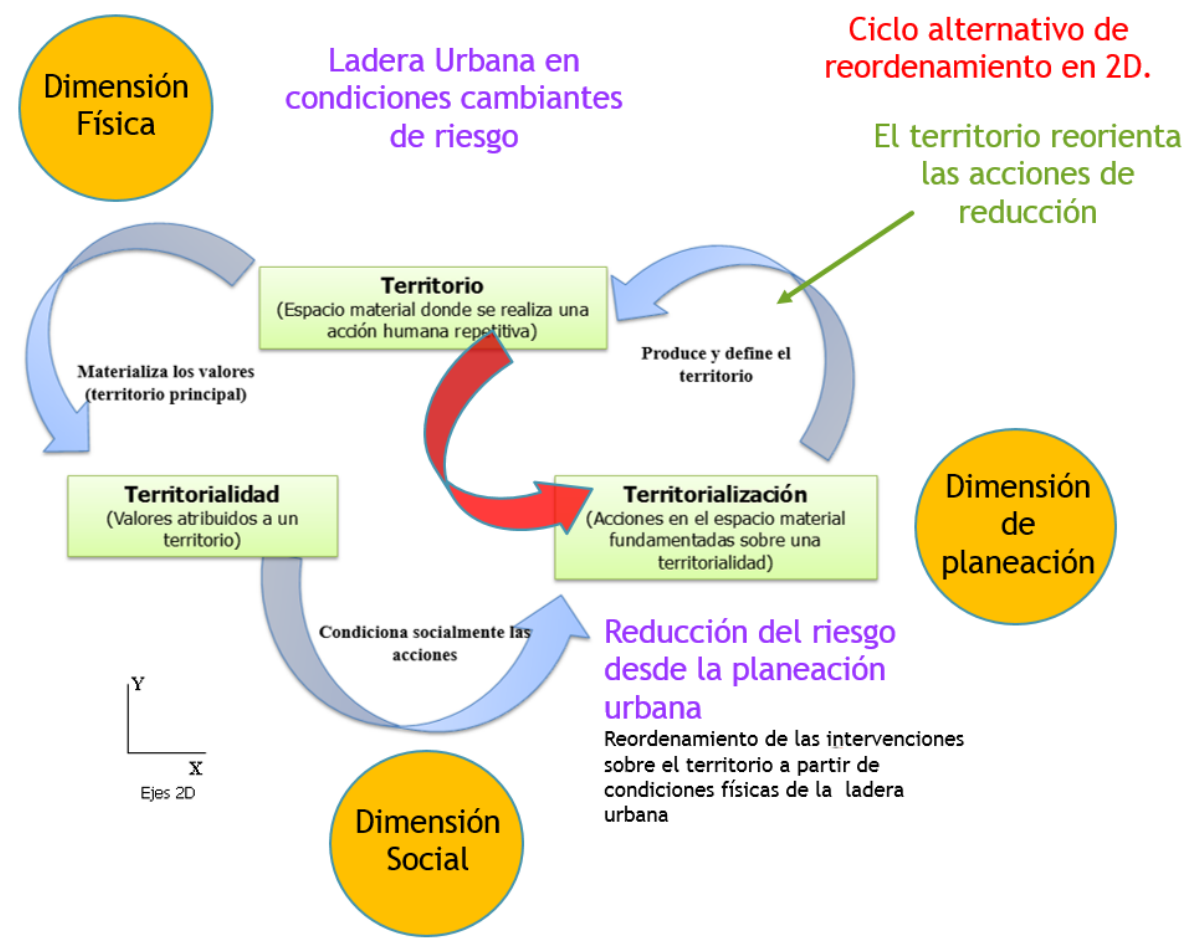

Figura 5: Análisis del ciclo alternativo de interdeterminación en la intervención de la planeación mediante reordenamiento de la intervención en 2D

Céspedes (2015: 43)

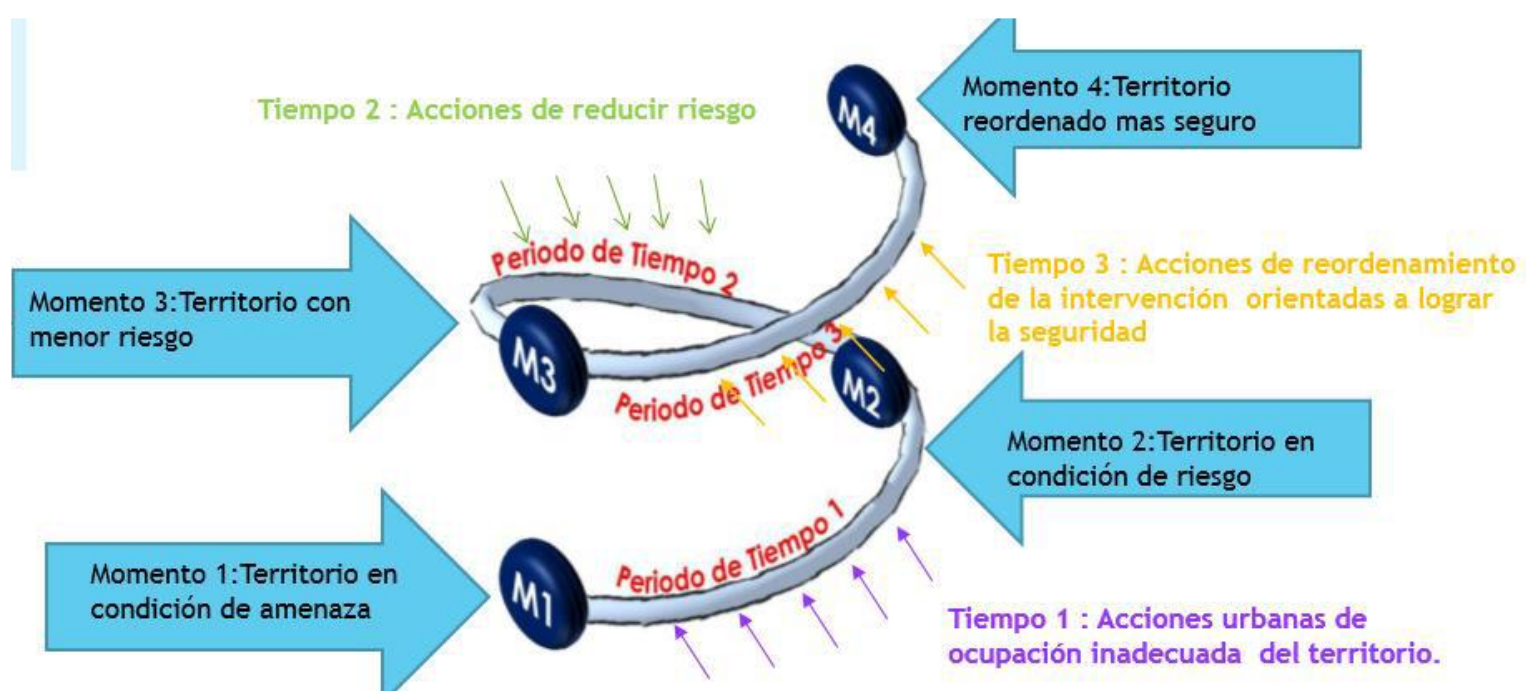

Figura 6: Camino prospectivo de la reducción del riesgo mediante reordenamiento en 3D (en la línea del tiempo) Céspedes (2015: 44). 


\section{Nuevo Territorio}

$\longrightarrow$ Cambios en la territorialidad

$\longrightarrow$ Acción de territorialización (reordenamiento)

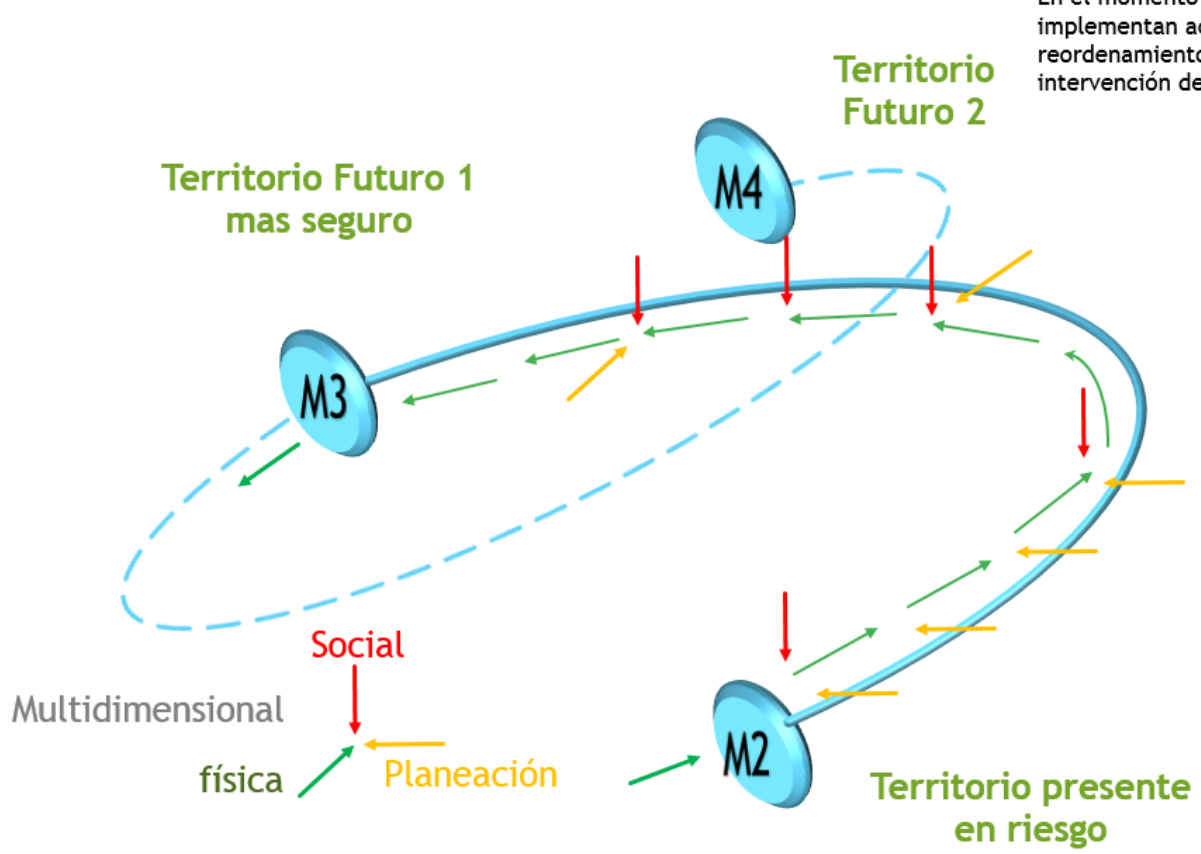

Ciclo del reordenamiento en 3D (componente

temporal )

En el momento 2 cuando se

implementan acciones graduales de

reordenamiento de la intervención e

Territorio

Futuro 2

de la territorialidad.

Figura 7: Análisis del ciclo de interdeterminación en el tiempo (3D) aplicado a la intervención de la ladera urbana en riesgo Céspedes (2015:45).

\subsection{Marlon Arias Sánchez o cómo pensar la ciudad de Bogotá D.C. desde la gestión del suelo}

El objetivo de la investigación de Marlon Arias Sánchez intitulada Bogotá D.C. durante el periodo 1998-2015 y su gestión del suelo. Una aproximación desde un enfoque de políticas públicas y el Derecho a la Ciudad era (Arias, 2016a):

... analizar la trayectoria de los instrumentos de gestión del suelo utilizados en la ciudad de Bogotá D.C., durante el periodo 1998-2015, mediante un enfoque de las políticas públicas con el fin, primero, de comprender los modelos de ciudad existentes en la práctica y, segundo, de revisar las intenciones expuestas por los diferentes gobiernos del Distrito a la luz del "derecho a la ciudad".

Apoyándose, entre otros, en Bejarano (2012), Arias presenta su propia interpretación del Trípode de Monnet (ver Figura 8) que se vuelve para él un ciclo que relaciona "el gobierno del territorio, la gobernabilidad en la territorialidad y la gobernancia de la territorialización". Así, explica Arias, se "combina a través de una balanza de poder el sistema socio-territorial [de Monnet] con las diferentes perspectivas del arte de gobernar".

\section{Arias concluye indicando que}

...la exposición de la dimensión política de cada una de las administraciones de la Alcaldía Mayor desde 1998 a través de la [Figura 9] "La ciudad como escenario complejo y dinámico", representa el flujo de valores-intenciones puestos en marcha durante el periodo de estudio para alcanzar-conservar el equilibrio en el territorio, con el fin de imprimir aproximaciones sobre la reflexión del modelo(s) de ciudad desarrollado en la Bogotá D.C. producto del proceso cognitivo, temporal y espacial, en el tránsito del dicho (intenciones), al hecho (instrumentos de acción pública), en un trecho (territorio) (ibídem. Cursivas originales).

Siguiendo su reflexión, Arias (2016b) elabora la Figura 9 que intitula "La ciudad como escenario complejo y dinámico". Dicha figura, indica,

...es la herramienta metodológica a tener en cuenta en el desarrollo de la investigación. Por medio de ésta se busca expresar el equilibrio creado por las diferentes administraciones del Distrito Capital en el periodo 1998-2015 para desarrollar el arte de gobernar 
en el territorio, sabiendo de antemano la inter-determinación existente y su conexión con algunos instrumentos de la acción pública (cursivas añadidas).

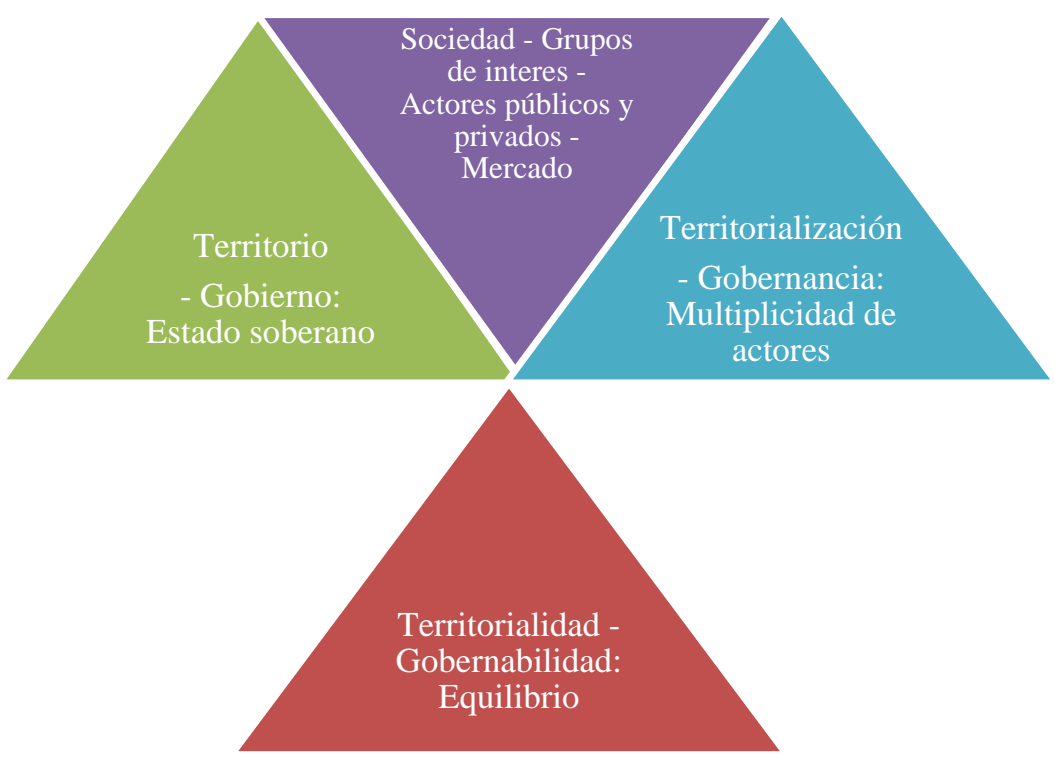

Figura 8: El gobierno del territorio, la gobernabilidad en la territorialidad y la gobernancia de la territorialización Arias (2016b:12).

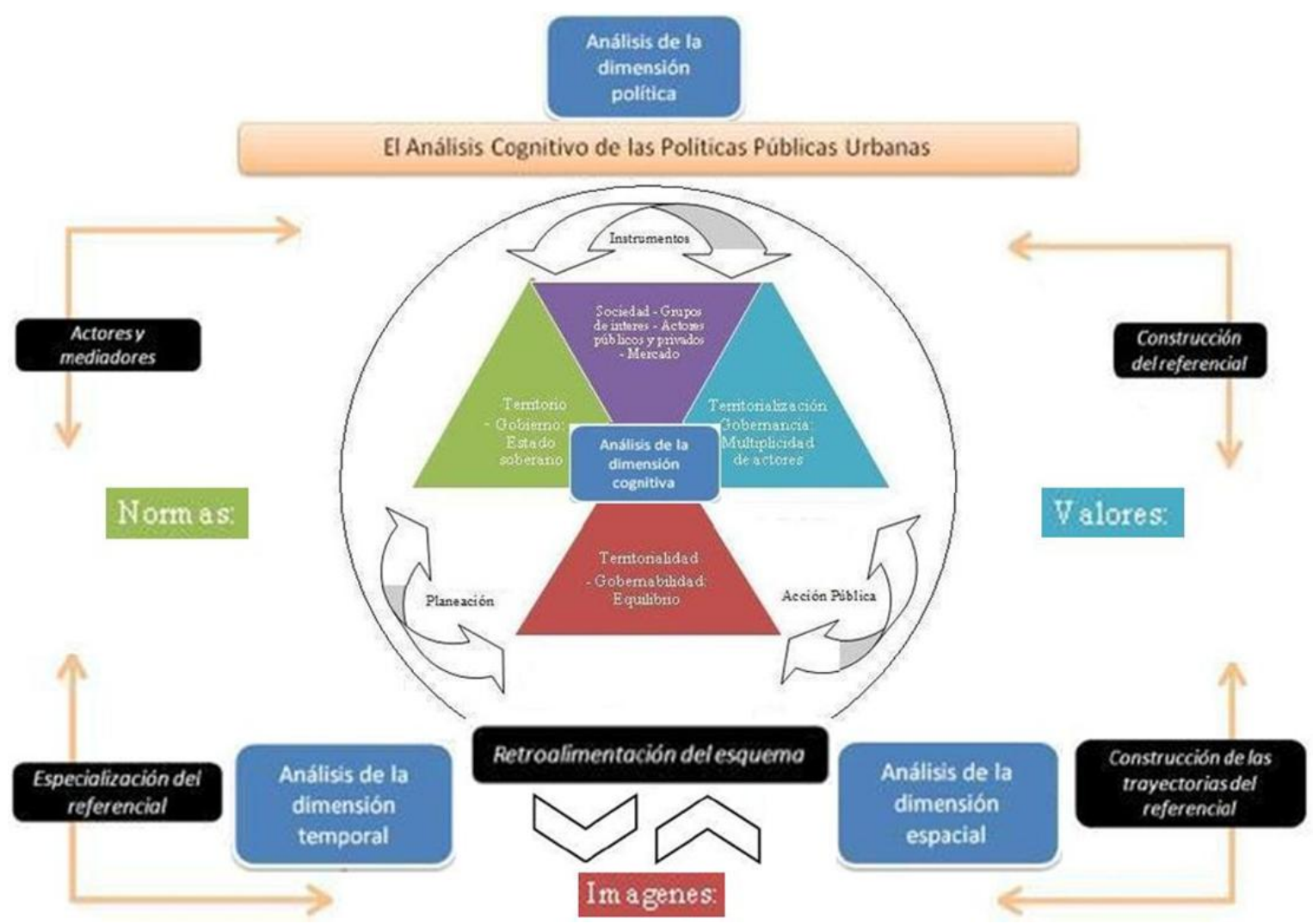

Figura 9: La ciudad como escenario complejo y dinámico Arias (2016b:12). 
Ley 152 de 1994, Ley Orgánica del Plan de Desarrollo
Ley 388 de 1997, Ley de Desarrollo Territorial

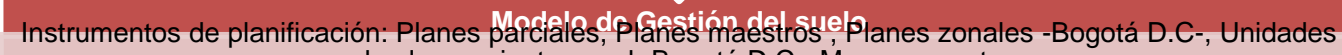
de planeamiento zonal -Bogotá D.C-, Macroproyecto

Instrumentos de financiamiento: Contribución de valorización-desarrollo, Participación en la plusvalía,

Pagarés y bonos de reforma urbana, Compensaciones, Transferencia de derechos de construcción y/o desarrollo, Anuncio de proyecto

Instrumentos de gestión: Unidades de actuación urbanística, Compensaciones, Transferencia de derechos de construcción y desarrollo, Reajuste de tierras, Integración inmobiliaria, Cooperación entre partícipes,

Enajenación voluntaria, Enajenación forzosa, Anuncio de proyecto, Expropiación (por vía judicial o

administrativa) Declaración de desarrollo prioritario, Derecho de preferencia, Bancos inmobiliarios.

Figura 10: Sistema de Planificación Urbana y Modelo de Gestión del suelo Arias (2016b:15).

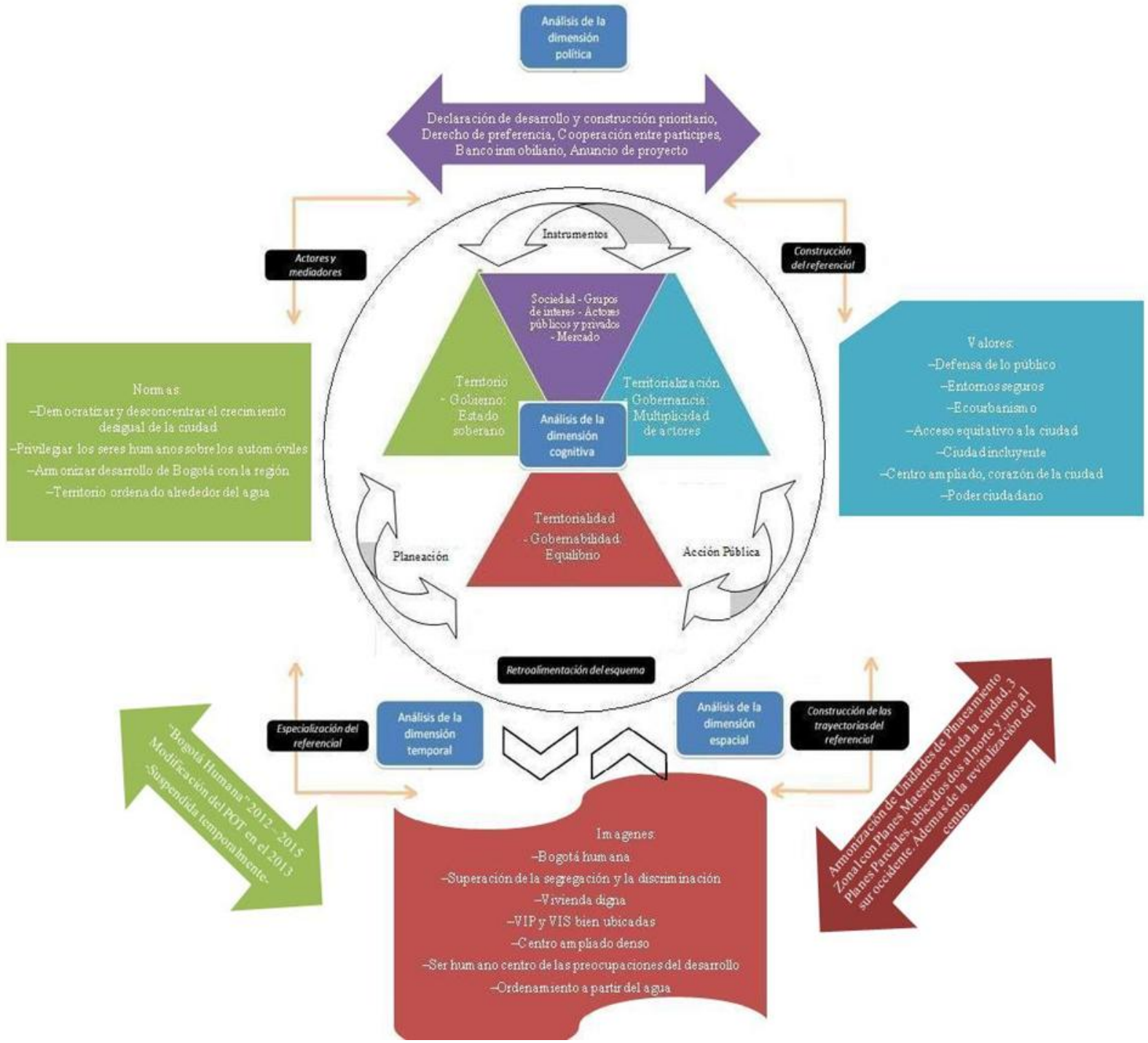

Figura 11: Gobernabilidad 2012-2016

Arias (2016a: 92). 
Hecha esta relación, puede entonces para cada una de las administraciones de Bogotá desde 1998 establecer

\begin{abstract}
...el análisis de la gobernabilidad en el territorio, tomando elementos brindados por cada una de las dimensiones propuestas por Bejarano (2012). A modo de resumen, la dimensión cognitiva abordó el referencial de cada administración, la cual articula su estructura de significación de la realidad según sus niveles de percepción del mundo: imágenes, normas y valores, para poner en evidencia las intenciones. La dimensión temporal reconoció la trayectoria en el tiempo de los diferentes instrumentos de la gestión del suelo usados en el territorio por cada administración de Bogotá D.C. en el periodo 1998-2015. La dimensión espacial rastreó la relación entre acción pública de los planes de desarrollo, los instrumentos de planificación, financiamiento y de gestión del suelo, con el espacio urbano, cuyo reconocimiento arrojó los focos de intervención de la acción pública en la ciudad (Arias, 2016b. Cursivas originales).
\end{abstract}

Ahora bien, para poder "pensar la ciudad a partir de la gestión del suelo", necesita, previamente, relacionar el "Sistema de Planificación Urbana" y el "Modelo de Gestión del suelo" en Bogotá (ver Figura 10).

La Figura 11 presenta el caso de la Administración de Gustavo Petro (2012-2016).

\title{
4 A MANERA DE REFLEXIONES CONCLUSIVAS: APORTES PARA ENTENDER, FORMULAR E IMPLEMENTAR POLÍTICAS PÚBLICAS URBANAS Y TERRITORIALES
}

Presentados algunos de los avances investigativos para el análisis de las políticas públicas urbanas a partir de los "Tres M" (Muller, Matus y Monnet) que ayudaron a mejor entender las complejas interrelaciones del "trinomio imperfecto" políticas públicas, planeación y territorio, es la hora de resaltar los aportes de estos avances investigativos para entender, formular e implementar políticas públicas urbanas y, más allá, territoriales como lo propone la recién aprobada "Agenda urbana" adoptada en la Declaración firmada al finalizar Conferencia de Naciones Unidas sobre Hábitat y Desarrollo Sostenible (Hábitat III) tenida en Quito (Ecuador) en octubre de 2016. Así, podrán las entidades territoriales y el nivel central del Estado responder a los desafíos de este inicio de siglo de dos maneras: los aspectos analíticos y las utilizaciones instrumentales de los avances investigativos.

- En cuento a los aspectos analíticos, tratados explícitamente en las investigaciones presentadas aquí y cuyos aportes son más bien de carácter conceptual (Bejarano, Gómez, Martínez), los aportes son importantes. Disponer, por ejemplo, de un esquema de análisis del referencial de las políticas públicas urbanas desde la perspectiva de los instrumentos de planificación y de gobierno como instrumentos de acción pública como el que elaboró Catalina Bejarano y que enriqueció Jorge Martínez y amplió Marlon Arias, constituye una herramienta fundamental para entender el por qué tanto de la acción pública urbana y territorial como de la planificación urbana y territorial. Este esquema, que permite abordar las "trayectorias del referencial de los instrumentos de acción pública", al decir de su autora, constituye "una metodología desde un enfoque cognitivo que permite estudiar las relaciones temporales de las políticas públicas en la ciudad y sus efectos en la territorialización" (Bejarano, 2012). Esta herramienta, sólidamente construida, ha servido por ejemplo a mejor "pensar" varios aspectos de la política de vivienda ${ }^{3}$. Cada una de las investigaciones al "aplicarla" a situaciones concretas, la ha enriquecido y desarrollado.

Igual ocurre con el prometedor camino que sigue abriendo Sandra Gómez sobre las formas de territorialización de los atributos urbanos y la discusión sobre territorio areolar y territorio reticular en la planeación territorial de los procesos de metropolización. He aquí un aporte fundamental a la hora de entender mejor la manera de pensar la "gobernanza metropolitana"...

- Pero las investigaciones cuyos aportes son más bien de carácter instrumental como la de Céspedes, abren una ventana nueva sobre la manera de "pensar" el riesgo y su gestión y de "intervenir" los barrios sometidos al mismo. Hay que invertir la "tradicional" o "clásica" visión de "introducir en los instrumentos de planificación la reducción de riesgo" por otra, "alternativa": "la planeación urbana como una medida de reducción del riesgo de desastres y de reordenamiento de un territorio de ladera urbana en riesgo". Así se abre un camino nuevo a los policy makers y a los planificadores territoriales, al permitirles tener herramientas para "pensar" con Matus no solo el "debe ser" sino "el hacer" y el "cómo hacer" y, más allá, considerar con Karol Cortes, otra miembro del Grupo PU citada por Céspedes, estas

\footnotetext{
${ }^{3}$ Para solo citar cuatro ejemplos de investigaciones desarrolladas en el Grupo PU: La política pública de reasentamientos de Bogotá y Soacha, Retos y desafíos del Programa de Mejoramiento Integral de Barrios de Bogotá, D.C. entre 2000 y 2012, La política nacional de vivienda19912014 y La políticas pública de vivienda del Distrito Capital (2 investigaciones).
} 
....acciones territoriales dentro de las cuales se encuentran las acciones mismas o instrumentos que territorializan, a partir de [un] sistema de valor, las transformaciones postuladas a futuro en el proceso de planificación y responsables de lograr los cambios.

Otro ejemplo, no menos significativo: solamente es porque ha sabido apoyarse en herramientas sólidamente construidas por el Grupo PU que Marlon Arias ha podido "pensar la ciudad desde la gestión del suelo y el Derecho a la ciudad". Logró para decirlo así "desintrumentalizar" los instrumentos de gestión del suelo y reubicarlos como lo que son: unos instrumentos de planeación, de acción pública y de gobierno que unen la "política" y la "política pública" y son la bisagra entre un proyecto político ("modelo de ciudad...") y el acto de gobernar como manera de lograr "la gobernabilidad territorial urbana"...

Queda, por cierto, mucha tarea por hacer, por ejemplo complementar la aproximación "desde los instrumentos" de planificación que ha sido la única desarrollada hasta hoy, con una aproximación "desde los actores"... Así se abrirá nuevo camino a la investigación sobre el "trinomio imperfecto" políticas públicas, planeación y territorio, sin necesariamente, como lo anota Sabina Gómez, tener que encontrar "una fórmula para resolver la relación óptima del conjunto"...

Al juicio del autor, los avances investigativos del Grupo PU constituyen un aporte significativo al campo, todavía poco explotado, del análisis de las políticas públicas urbanas, al ofrecer tanto a los académicos como a los policy makers una propuesta de marco en construcción y, por cierto, matizable, discutible y mejorable... Dicho marco permitirá mejor tanto entenderlas (aspectos analíticos) como formularlas e implementarlas (utilizaciones instrumentales). Así, por ejemplo, se avanzará sobre la, todavía, borrosa cuestión de la sostenibilidad urbana, respondiendo sus desafíos y dándole las bases conceptuales para trazar nuevas estrategias...

Es el deseo del autor de esta presentación y del Grupo PU que tanto los académicos del análisis de las políticas públicas urbanas como la sociedad que las formula, las implementa y las planifica, critiquen, debaten de estos avances investigativos y, sobre todo, los completen con sus propias investigaciones.

\section{BIBLIOGRAFIA}

ARIAS SÁNCHEZ, Mar. (2016a). Bogotá D.C. durante el periodo 1998-2015 y su gestión del suelo. Una aproximación desde un enfoque de políticas públicas y el Derecho a la Ciudad, Trabajo de grado para optar por el título de Magister en Estudios Políticos (JOLLY, J.-F., director), Grupo de investigación interfacultades "Políticas urbanas".

(2016b). Pensar la ciudad de Bogotá D.C. desde la gestión del suelo. Una aproximación socio-territorial durante el periodo 1998-2015. Foro sobre políticas públicas, planeación y territorio. A propósito de los trabajos de Jérôme Monnet, Bogotá, 28 de abril (no publicado).

BEJARANO MAYORGA, Ca. 2012. Hacia un esquema para el análisis del referencial de las políticas públicas urbanas, desde la perspectiva de los instrumentos de planificación y de gobierno, como instrumentos de acción pública, Trabajo de grado para optar por el título de Magístra en Planeación Urbana y Regional (JOLLY, J.-F., director), Grupo de investigación interfacultades "Políticas urbanas".

(2013). Un esquema de análisis de las trayectorias de las políticas públicas en el territorio. VII ${ }^{\circ}$ Congreso Latinoamericano de Ciencia Política, organizado por la Asociación Latinoamericana de Ciencia Política (ALACIP), Bogotá, 25-27 de septiembre.

(2016). Un esquema de análisis de las trayectorias de las políticas públicas en el territorio. Foro sobre políticas públicas, planeación y territorio. A propósito de los trabajos de Jérôme Monnet, Bogotá, 28 de abril (no publicado).

CÉSPEDES, N. A. (2015). Propuesta de análisis de las condiciones para el reordenamiento de una ladera urbana, desde la perspectiva de la planeación de la ciudad como medida para la reducción del riesgo de desastres en Colombia. Ilustración con el caso de la ladera urbana del municipio de Bucaramanga, Trabajo de grado para optar por el título de Magístra en Planeación Urbana y Regional (JOLLY, J.-F., director), Grupo de investigación interfacultades "Políticas urbanas".

(2016). Reordenar un territorio de ladera urbana en riesgo en Colombia, un ejercicio de planeación Foro sobre políticas públicas, planeación y territorio. A propósito de los trabajos de Jérôme Monnet, Bogotá, 28 de abril (no publicado).

DORMOIS, R. (2015). Les politiques urbaines : Histoire et enjeux contemporains, Rennes, Presses Universitaires de Rennes. 
DOUILLET, A. C et al. (2015). Trois regards sur les politiques vues du local, Une «French touch » dans l'analyse des politiques publiques ?, BOUSSAGUETL et al. (edit.), Paris, Presses de Sciences Po, pp. 319-347.

GÓMEZ, S., (2012). Un trinomio imperfecto: territorio, planeación e instituciones: Un acercamiento a propósito del manejo territorial en Colombia, Trabajo de grado para optar por el título de Magístra en Planeación Urbana y Regional (JOLLY, J.-F., director), Pontificia Universidad Javeriana-Bogotá, Grupo de investigación interfacultades "Políticas urbanas".

(2013). La territorialización de la acción pública y el enfoque institucionalista: algunos elementos de análisis y su pertinencia en los procesos de construcción de región y áreas metropolitanas en Colombia,.VII ${ }^{\circ}$ Congreso Latinoamericano de Ciencia Política, organizado por la Asociación Latinoamericana de Ciencia Política (ALACIP), Bogotá, 25- 27 de septiembre.

(2016). Las implicaciones de la distinción entre territorio areolar y reticular en la planeación territorial de los procesos de metropolización. Foro sobre políticas públicas, planeación y territorio. A propósito de los trabajos de Jérôme Monnet, Bogotá, 28 de abril (no publicado).

JOLLY, J.-F. (2008). Régir le territoire et gouverner les territoires. Décentralisation et territorialisation des politiques publiques en Colombie, Paris, L'Harmattan.

(2010). Regir el territorio y gobernar los territorios. Políticas públicas de vivienda de interés social, servicios públicos domiciliarios y educación, Bogotá, Editorial Pontificia Universidad Javeriana.

(2012). La interdeterminación entre territorio, territorialidad y territorialización de las políticas públicas. Hacia una nueva propuesta de esquema para el análisis de las políticas públicas en el territorio". $\mathrm{VI}^{\circ}$ Congreso Latinoamericano de Ciencia Política, organizado por la Asociación Latinoamericana de Ciencia Política (ALACIP), Quito, Ecuador 12-14 de junio, y XVII Congreso Internacional del CLAD sobre la Reforma del Estado y de la Administración Pública, Cartagena, Colombia, 30 de octubre-2 de noviembre, http://www.dgsc.go.cr/dgsc/documentos/cladxvii/jollyjea.pdf,(Consulta el 22 de junio de 2016).

(2013a). A propósito del "trinomio imperfecto" políticas públicas, planeación y territorio. Algunas reflexiones sobre el desarrollo de un esquema para el análisis de las políticas públicas en el territorio fundamentado en la interdeterminación entre territorio, territorialidad y territorialización de las políticas públicas. VII ${ }^{\circ}$ Congreso Latinoamericano de Ciencia Política, organizado por la Asociación Latinoamericana de Ciencia Política (ALACIP), Bogotá, 25- 27 de septiembre.

(2013b). Una experiencia académica original: el grupo de investigación inter facultades "políticas urbanas". Revista Javeriana (por publicarse).

(2014). A propósito del "trinomio imperfecto" políticas públicas, planeación y territorio. Algunas reflexiones sobre el desarrollo de un esquema para el análisis de las políticas públicas en el territorio fundamentado en la interdeterminación entre territorio, territorialidad y territorialización de las políticas públicas, $\mathrm{VI}^{\circ}$ Seminario Internacional de Investigación en Urbanismo [VISIIU] Bogotá-Barcelona, Bogotá, 34 de

junio, http://upcommons.upc.edu/bitstream/handle/2099/15976/061 BGT Jolly JeanFran\%C3\%A7ois.pdf?seque nce $=1$ \&isAllowed $=y$ (Consulta 22 de junio de 2016).

(2015a). La interdeterminación entre territorio, territorialidad y territorialización de las políticas públicas. Hacia una nueva propuesta de esquema para el análisis de las políticas públicas en el territorio. En Ensayos sobre políticas públicas II (Jorge Iván Cuervo, editor), Bogotá, Universidad Externado, pp. 271-309. (2015b). A propósito del "cuadrinomio imperfecto" desarrollo humano, políticas públicas, planeación y territorio. Algunas reflexiones sobre el desarrollo de un esquema para el análisis de las políticas públicas en el territorio fundamentado en la interdeterminación entre territorio, territorialidad y territorialización de las políticas públicas. En Desarrollo: prácticas y discursos emergentes en América Latina, Grupo de Trabajo CLACSO “NUEVAS PERSPECTIVAS SOBRE EL DESARROLLO Y POLÍTICA PÚBLICA”, pp. 85-121.

LE GALĖS, Pa. 1995, Du gouvernement des villes à la gouvernance urbaine. Revue française de science politique, Vol. 45, № 1, pp. 57-95.

MATUS, C. (1987). Política, planificación y gobierno. Segundo borrador, Washington, Organización Panamericana de la Salud (OPS) y Instituto Lationamericano y del Caribe de Planficación Económica y Social (ILPES).

(1992). Política, planificación y gobierno, Caracas, Fundación Altadir.

MARTíNEZ CARVAJAL, Jo. En. (2013a). Hacia un esquema de análisis de la formulación de la política social de salud pública desde un enfoque socio-territorial temporal a partir de los instrumentos de planificación, Trabajo de grado para optar por el título de Magister en Política Social (JOLLY, J.-F., director), Grupo de investigación interfacultades "Políticas urbanas". 
(2013b). La formulación de la política social de salud pública desde un enfoque socio-territorial temporal a partir de los instrumentos de planificación. VIIํ Congreso de ALACIP, Bogotá, 2527 de septiembre.

(2016). Articulación de la política de salud pública desde un enfoque socioterritorial temporal en las ciudades de Medellín y Bogotá para el período 2004-2016. Foro sobre políticas públicas, planeación y territorio. A propósito de los trabajos de Jérôme Monnet, Bogotá, 28 de abril (no publicado).

MONNET Jé. (2010). Le territoire réticulaire, Anthopos, huellas del conocimiento, Número 227, pp.91-104.

MULLER, Pi. (1997). Un esquema de análisis de las políticas públicas sectoriales. Tecnología Administrativa, vol. $\mathrm{XI}$, No. 23.

(2010). Las políticas públicas, $3^{a}$ edición en español, Bogotá, Universidad Externado de Colombia.

ROA BERNAL, Lu. Pa. (2011a). La territorialidad de los derechos humanos. La planeación del desarrollo territorial, un instrumento para su territorialización, Trabajo de grado para optar por el título de Magístra en Planeación Urbana y Regional (JOLLY, J.-F., director), Grupo de investigación interfacultades "Políticas urbanas".

(2011b). La incorporación de los derechos humanos en el referencial de las políticas públicas de ciudad, una alternativa para la reivindicación de la dignidad humana en la ciudad. Coloquio INJAVIU "La dignidad humana en la ciudad latinoamericana: Reflexiones para un nuevo paradigma de intervención en el territorio", Bogotá, D. C., 26 -28 de octubre (inédito). 